\title{
A ATOMIZAÇÃO DO SENTIDO DE SOCIEDADE CIVIL
}

\author{
Luiz Carlos Tavares ${ }^{1}$
}

\section{RESUMO}

$\mathrm{Na}$ atualidade, os paladinos das políticas neoliberais passaram a entender que as lutas sociais de hoje são o reflexo de uma sociedade erigida por uma multiplicidade de vozes e pluralismo de posições. Essa é uma concepção advinda do pensamento pósmoderno, que junto a sua particular maneira de interpretar a realidade traz na narrativa do fim da civilização ocidental e de seus valores dominantes, o fio condutor para se traçar uma nova perspectiva de compreensão e atualização da realidade social. É diante desse contexto que situamos o objeto de pesquisa aqui adotado: a sociedade civil e sua interpretação pós-moderna. As lutas populares e as contestações sociais são indicadores de uma condição estabelecida pelo capital, que é a da contradição classista, e nesse processo o ato da luta política só pode se transformar em unidade transformadora à medida que deriva de um movimento em direção à consciência de classe. Desse modo, um dos principais objetivos aqui dimensionados situa-se em tentar compreender como a diversidade, ou ainda, a identidade, ambas rotuladas pela leitura pós-moderna como fragmentárias e individualistas, podem se transformar em uma identidade totalizadora, a de classe, quando movida pela força motriz de superação do capital. Com o processo de globalização, ou ainda, mundialização do capital, como prefere Chesnais (1996), houve um considerável agravamento das condições de vida da população mundial, o que produziu como reflexo imediato uma serie de transformações econômicas e políticas. E nesse bojo, o pensamento pós-moderno surge como instrumento de (re)organização e interpretação do "novo" momento vivido pelo capitalismo mundial e por sua forma de desenvolvimento, estando no centro dessa reorientação interpretativa a negação da centralidade do trabalho e do conceito de classes. É neste ínterim que se busca justificar a validade e a necessidade de uma reflexão teórica que faça o contraponto à visão reducionista e maniqueísta do posicionamento pós-moderno de entendimento da realidade atual. Este empreendimento teórico é um desdobramento da dissertação de mestrado intitulada: "Participação Social e Política de Desenvolvimento Territorial: a produção de uma sociabilidade estabelecida pelo consenso", defendida em setembro de 2014 na Universidade Federal de Sergipe. Para tanto, se fez necessário um grande esforço no sentido de traçar uma investigação bibliográfica que desse conta de conceitos como, classes sociais, sociedade civil, pós-modernidade, neoliberalismo e identidade. O método foi o dialético, com ênfase na lei dialética da unidade e luta dos contrários. A investigação e o debate aqui travado deixam claro que os pós-modernos possuem uma intencionalidade muito bem definida, a de patrocinar e legitimar processos de individualização humana, deturpando a validade do conceito de classes em detrimento de uma eloquente valorização de termos fragmentadores da realidade.

Palavras-chave: Sociedade Civil. Identidade. Classes Sociais.

${ }^{1}$ Graduado em Geografia pela Universidade Federal de Sergipe Campus Professor Alberto Carvalho. Especialista em Libras e Inclusão pela Faculdade Tobias Barreto. Mestre em geografia pela Universidade Federal de Sergipe. O presente artigo é desdobramento das discussões empreendidas em minha dissertação de mestrado. Email: luiz.geografia@ hotmail.com. 


\section{ABSTRACT}

In actuality, the paladins of neoliberal policies have come to understand that the social struggles of now are a reflection of a society built by a multiplicity of voices and pluralism of positions. This is a conception derived from postmodern thought, which, with its particular way of interpreting reality, brings the narrative of the end of Western civilization and its dominant values, the common thread to chart a new perspective and understanding of updating the social reality. It is against this context that we situate the research object adopted here: civil society and its postmodern interpretation. Popular struggles and social challenges are indicators of a condition set by the capital, which is a classist contradiction, and in this process the act of political struggle can only turn into manufacturing unit as derived from a movement toward awareness class. Thus, a major goal dimensioned here lies in trying to understand how the diversity, or even identity, both labeled by postmodern reading as fragmented and individualistic, can turn into a totalizing identity, class identity, when moved by the driving force to overcome the capital. With the process of globalization, or even globalization of capital, as Chesnais (1996) prefers, there was a considerable deterioration of living conditions of world population, what has produced immediate impact as a series of economic and political transformations. And that bulge, postmodern thought arises as a tool for (re) organization and interpretation of the "new" moment experienced by global capitalism and its way of development, being at the heart of this interpretative reorientation the denial of the centrality of work and the concept of class as the motor of history. It is in this interim that we seek to justify the validity and the need for a theoretical reflection that makes the counterpoint to reductionism and Manichaean view of the postmodern position of understanding the current reality. The discussion here is an offshoot of the dissertation entitled: "Social Participation Policy and Territorial Development: the production of a sociability established by consensus", held in September of 2014 at the Federal University of Sergipe. The production of this article focused on a bibliographic research that discusses concepts such as social class, civil society, postmodernism, neoliberalism and identity. The method used was the dialectical, with emphasis on the dialectical law of unity and struggle of opposites. The research and the debate we have made try to show that postmodernists have a very definite intention, to sponsor and legitimate processes of human individuation, misrepresenting the validity of the concept of classes rather than an eloquent appreciation of shredders terms of reality.

Keywords: Civil Society. Identity. Social Classes. 


\section{Introdução}

De acordo com Wood (1995), a pós-modernidade é apresentada como um movimento/ciclo natural de superação de uma civilização por outra imediatamente superior, resultando da obsolescência dos ideais "iluministas" de "esclarecimento", em detrimento da emergência de um sistema social de individualismo e niilismo cultural. Segundo esse pensamento "o capitalismo é a realização do paraíso na terra e, por isso, a história chegou ao seu fim. Os males e as misérias que observamos nos dias de hoje não são o resultado desse sistema econômico e social, mas da sua ausência" (CARCANHOLO, 2008, p. 10). As contradições reinantes na sociedade do capital não teriam em seu normal metabolismo a sua explicação, mas em sua má realização, e por assim dizer, em uma disfunção pontual e reversível.

O pensamento pós-moderno é posto no sentido de desautorizar a atualidade do pensamento moderno, o atacando em suas diversas formas e direções. Os pós-modernos referenciam o pensamento moderno como extremamente positivista, tecnocêntrico e racionalista, que fruto da crença no progresso linear da história, representaria ideais pautados em verdades absolutas, na padronização do conhecimento e da produção e planejamento racional de ordens sociais ideais (HARVEY, 1998). E desse modo, o pensamento pós-moderno ao promover a dissolução do que se põe por moderno, promove um conteúdo discursivo que celebra o fragmentário, o heterogêneo e a diversidade, passando a refutar todos os desdobramentos de um pensamento resultante da metanarrativa, mesmo que seja este a luta de classes, ou quaisquer perspectivas de superação do modelo capitalista. Diante dessa tessitura, conclui-se que a abordagem pós-moderna tenta desconstruir uma realidade reificante, que é a do capital, da mercadoria.

\section{O reducionismo fragmentário de um conceito totalizador}

Abster-se dos pressupostos do pensamento moderno e colocá-lo na contramão da história e de toda a forma explicativa da totalidade das relações, seria no mínimo subestimar a possibilidade de ler a realidade a partir das contradições, e por isso, negligenciar a importância explicativa do totalizador conceito de classes. 
Enquanto existir capitalismo, ele produzirá classes dominantes e subalternos explorados. Se não formos capazes de analisar como ocorre a extração do sobretrabalho (econômica, social, política e culturalmente), perderemos de vista as classes dominadas e, assim, seremos presa fácil da nada generosa conviç̧ão de que acabaram as classes sociais e... a História (FONTES, 2006, p. 203).

Diante do pensamento pós-moderno, o entendimento de classes sociais deixa de ter na metanarrativa o eixo principal de sua elucidação, para dar lugar a representações que atribuem a "identidade" e a existência de uma sociedade civil altamente bem articulada com as diretrizes do mundo capitalista, papeis privilegiados diante da sociabilidade capitalista.

Por mais diferentes que sejam os métodos para dissolver conceitualmente o capitalismo - o que inclui tudo desde a teoria do pós-fordismo até os "estudos culturais" pós-modernos e a "política de identidade" -, eles em geral têm em comum um conceito especialmente útil: "sociedade civil". Depois de uma história longa e tortuosa, depois de uma série de marcos representados pelas obras de Hegel, Marx e Gramsci, essa ideia versátil se transformou numa expressão mágica adaptável a todas as situações da esquerda, abrigando uma ampla gama de aspirações emancipatórias, bem como - é preciso que se diga um conjunto de desculpas para justificar o recuo político. Por mais construtiva que seja essa ideia na defesa das liberdades humanas contra a opressão do Estado, ou para marcar o terreno de práticas sociais, instituições e relações desprezadas pela "velha" esquerda marxista, corre-se o risco hoje de ver "sociedade civil" transformar-se num álibi (WOOD, 2011, p. 205).

A generalização de movimentos relacionados à raça, à sexualidade, à etnia, à identidade e outros, justificam-se pela dissimulada importância deslocada para a defesa da diversidade e da multiplicidade de opressões existentes da sociedade atual. Esta realidade passa a ser entendida pelos defensores da pós-modernidade como o alargamento da sociedade civil, o que dissolve a importância do potencial políticoemancipatório existente na condição de classe. 
Os PÓS-MODERNOS, INDUZIDOS pelo processo de individualização humana cada vez mais crescente no capitalismo apegam-se ao conceito de identidade como clara intenção de colocá-lo em destaque, sobrepondo-o ao conceito de classes sociais (BOGO, 2010, p. 9).

Os apologistas do discurso pós-moderno agem no sentido de fragmentar o poder da explicação marxista de sociedade civil, ao afirmar que sua conceituação se estabelece por meio de um reducionismo economicista que priva a complexidade pertencente ao seu entendimento, já que se reduz ao "modo de produção", à economia capitalista.

Para Wood (2011) esse reducionismo é em sua essência uma grande arma a favor do capital e de sua lógica totalizadora. Em sua análise, o conceito de sociedade civil passa a emergir a partir do discurso dominante como um código ou máscara para o capitalismo, uma vez que desarticula a lógica totalizadora e o poder coercitivo do capitalismo a partir de uma perspectiva discursiva que celebra o poder do fragmentário ${ }^{2}$, fazendo da sociedade civil um conceito altamente abrangente, "que a tudo cobre, desde os lares e as associações voluntárias até o sistema econômico do capitalismo, ou seja, confunde e disfarça tanto quanto revela" (Idem, p. 2010).

Sob a ênfase do fragmentário e da diversidade, há uma grande valorização das possibilidades advindas de um capitalismo humanizado, uma vez que são dissolvidas as relações de exploração e coerção a partir da negação do movimento das contradições. Esta é a sociedade pós-moderna, na qual a crescente fragmentação, diversidade de relações e experiências, assim como a pluralidade de identidades pessoais, dissolvem e anulam todas as antigas certezas e suas universalidades. Os pós-modernos afirmam que a crise moral de nosso tempo é antes um resultado do pensamento iluminista, que desprovido de atualidade, esteve a vigorar como arcabouço revolucionário e

${ }^{2}$ A intencionalidade desse processo de fragmentação é a de mascarar um modo de produção totalizador, excludente e concentrador, que é o capitalista. O sistema do capital passa a ser reduzido a um conjunto de instituições e relações, onde ao passo que faz desaparecer o conceito de capitalismo desagrega a sociedade em fragmentos. Nega ainda o caráter totalizador do sistema ao atestar e existência de outra estratificação social que não a de classes, outras lutas social que não as de classes, revelando uma sociedade fragmentária e repleta de relações sociais que não caminham pela seara das classes. Desconsidera-se que classe não é uma estratificação, mas antes, um processo social distinto, resultante da dinâmica de acumulação e de expansão do capital. 
emancipador diante das amarras da comunidade e das relações postas pelo período da Idade Média, mas que é hoje, fonte de formas ultrapassadas de compreender a complexidade social existente.

David Harvey (1998), em seu livro: “Condição pós-moderna: Uma Pesquisa sobre as Origens da Mudança Cultural" propõe uma série de questionamentos acerca do que realmente viria a representar o discurso pós-moderno, ou pós-modernista.

O pós-modernismo [...] representa uma ruptura radical com o modernismo ou é apenas uma revolta no interior deste último contra certa forma de "alto modernismo" representada, digamos, na arquitetura [...] e nas superfícies vazias da pintura expressionista abstrata minimalista? Será o pós-modernismo um estilo [...] ou devemos vê-lo estritamente como um conceito periodizador (no qual debatemos se ele nasceu nos anos 50,60 ou 70). Terá ele um potencial revolucionário em virtude de sua oposição a todas as formas de metanarrativa (incluindo o marxismo, o freudismo e todas as modalidades de razão iluminista) e da sua estrita atenção a "outros mundos" e "outras vozes" que há muito estavam silenciados (mulheres, gays, negros, povos colonizados com sua história própria)? Ou não passa da comercialização e domesticação do modernismo e de uma das aspirações já prejudicadas deste a um ecletismo mercado pelo "vale tudo", pelo laissez-faire? Portanto, ele solapa a política neoconservadora ou se integra a ela? E associamos a sua ascensão a alguma reestruturação radical do capital, à emergência de alguma sociedade "pós-industrial", vendo-o até como a "arte de uma era inflacionária" ou como a "lógica cultural do capitalismo avançado" (HARVEY, 1998, p, 47).

Situar-se diante desse processo construído discursivamente como hegemônico, requer uma análise que não caia em um objetivismo prático de respostas rápidas e simplórias, sua compreensão exige cautela e rigor analítico. Para Iasi (2011) entender que as classes definem as identidades coletivas, no sentido auferido por Marx, seria compreender "[...] a sociedade atual como uma sociedade capitalista e que o metabolismo essencial do capital, ainda que na forma avançada, segue determinando uma oposição irreconciliável entre capital e trabalho" (2011, p. 102).

A negação dessa compreensão tem contribuído para que o conceito de classes passe a ser alvo de diversas contestações e, dentre elas, a que questiona sua validade para responder a realidade contemporânea. Por 
ter sido elaborada no século XIX, e por isso, situada em um período histórico da sociedade industrial de seu tempo, questiona-se sua validade atual, essencialmente devido à complexidade do mundo do trabalho.

Segundo a compreensão de Iasi (2011) as interpretações que questionam a validade do conceito de classes em Marx seguem um erro em comum, o de capturar de maneira errada a forma como Marx trabalhava "conceitos". "[...] Marx não é um pensador do qual podemos esperar conceitos bem ao gosto de manuais do tipo "isto é:...", “aquilo é:..."” (2001, p. 104). Segundo Iasi, o que há em Marx é um conjunto de determinações particulares, que juntas constituem a definição do fenômeno de classe. E é justamente no esforço de quebrar com a visão mecanicista do entendimento de classes em Marx, que Iasi faz uma aproximação daquelas determinações que apreendidas no conjunto de suas obras nos possibilitaria entender o conceito de classes. Seriam elas:

1. Classe seria definida, num determinado sentido, pela posição diante da propriedade, ou não propriedade, dos meios de produção;

2. Pela posição no interior de certas relações sociais de produção (conceito que foi quase que generalizado como único);

3. Pela consciência que se associa ou distancia de uma posição de classe;

4. Pela ação dessa classe nas lutas concretas no interior de uma formação social (op. cit. p. 107).

Dessa maneira fica claro que o conceito de classes não pode ser lido limitando-se a determinações isoladas, apenas o contexto, a trama dos acontecimentos, a síntese das particularidades e sua relação com outras determinações nos possibilitam chegar ao entendimento de um conceito que é antes de tudo relacional. Restringir o conceito de classes a uma ou outra determinação é um risco que se incorre para a compreensão desse fenômeno.

Diante do cenário de contestação da validade do conceito de classes, a própria noção de poder passa a ser afetada por uma tendência de relativização e fragmentação das relações sociais. Influenciada pelas ideias de Foucault (1979), a concepção de poder passa a ser 
caracterizada pelo que chama de condição ascendente do poder. A partir dessa condição as transformações do domínio político e da estrutura econômica deixam de ser essenciais no trajeto em caminho às conquistas sociais. O poder, historicamente exercido pelo Estado e pelo capital, e possibilitador da manutenção da sociedade de classes, através da desigual organização societal entre possuidores e expropriados dos meios de produção, passa a ser apreendida nesse contexto como pertencente a toda relação.

As ideias de Foucault são fonte de pura inspiração ao discurso pósmoderno. Em seus escritos, as relações de poder só possuem efeitos positivos se forem diferentes das forças de resistência do tipo (marxista) que, absolutamente ligadas às mesmas técnicas e sistemas de conhecimentos do modo de produção capitalista, acabam sendo absolvidas e prejudicadas em sua proposta revolucionária. O poder do discurso humano, em sua ação multifacetada e pluralista seria a forma mais eficiente no embate ao capitalismo global, o que se faz sem necessariamente recorrer a nenhum modelo geral abrangente que, preso à mesma racionalidade-técnica repressiva do modelo combatido, teria já em sua formação a causa de seu fracasso.

Diante dessa tessitura, Harvey (1998) discorre sobre o pensamento de Foucault.

[...] O cuidadoso escrutínio da micropolítica das relações de poder em localidades, contextos e situações distintos leva-o a concluir que há uma íntima relação entre os sistemas de conhecimento ("discursos") que codificam técnicas e práticas para o exercício do controle e do domínio sociais em contextos localizados particulares. [...] uma organização dispersa e não integrada é construída independentemente de qualquer estratégia sistemática de domínio de classes (1998, p. 50).

Ao propor o combate às forças de opressão por caminhos que não os do próprio sistema, de sua burocracia, se obtém uma severa crítica às conquistas iluministas. Dessa maneira, conquistas como a do progresso científico tecnológico, da difusão do ensino universal, e a própria racionalização buscada pela burocracia e pela tecnologia, passam a ser interpretadas como empecilhos à substantivação da liberdade humana (WOOD, 1995). Em detrimento da elevação da importância do fragmentário e das possibilidades contingenciais, nega-se a existência tanto de um "sistema social" quanto de qualquer lei de funcionamento 
do sistema do capital. A negação da existência de um sistema social aponta justamente para a conformação de uma sociabilidade onde tudo se organizaria a partir dos particularismos fragmentados, onde o concreto não é o resultado da síntese, mas de ações isoladas e desconectadas da totalidade histórica.

\begin{abstract}
Há somente muitos tipos diferentes de poder, opressão, identidade e "discurso". Não apenas temos que rejeitar as antigas "grandes narrativas", como os conceitos iluministas de progresso, mas devemos renunciar a qualquer idéia de processo e causalidade histórica inteligível e, com isso, evidentemente, a toda idéia de "fazer história". Só existem diferenças anárquicas, desconectadas e inexplicáveis. Pela primeira vez, estamos diante de uma contradição em termos: uma teoria de mudança de época histórica, baseada na negação da história (WOOD, 1995, p. 122).
\end{abstract}

A negação da história e qualquer tipo de sistema e estrutura criam uma problemática interessante à manutenção da realidade posta, e suas contradições fundantes. Uma vez não havendo história e estruturas susceptíveis a uma análise causal, não haverá também como se chegar às raízes estruturais das relações opressoras, descaracterizando assim qualquer forma de oposição unificada de contestação às relações dominantemente capitalistas. Oposições do tipo marxista são absurdamente convertidas em formas de manifestações particulares, e assim elevam-se as possibilidades de ganhos e conquistas junto à ordem capitalista. Possibilidades otimistas sublimam-se frente às permanentes contradições do sistema do capital.

A partir desse contexto, a sociedade civil passa a ser sobrevalorizada, sendo a esfera da diversidade a maior representante daquilo que passaria a caracterizá-la. O movimento de contrários que passa a ser inteligível é o da diversidade, da pluralidade e não o das classes, perdendo-se de vista tanto a historicidade presente nas relações sociais quanto a unidade dialética existente nas mesmas. De acordo com Konder (2009):

Sob o capitalismo, a humanidade desenvolvera extraordinariamente o seu domínio da realidade natural, mas sacrificara ainda mais profundamente do que em épocas precedentes o seu domínio da realidade social. [...] A perspectiva de alguém que permaneça inteiramente imergido na realidade histórica do capitalismo, a perspectiva de alguém que não possa fazer a crítica desta realidade senão a partir da 
apreensão empírica e limitada dela, isto é, a perspectiva de alguém não entrosado com o movimento histórico imanente que a supera na prática e que permite vê-la a partir de um ponto de vista que não é o dela mesma, será necessariamente uma perspectiva capaz de ensejar apenas formas a-históricas (e, portanto, ilusórias) de transcendência da realidade social capitalista (2009, p. 129-130).

É nessa direção que o processo de perda do sentido de movimento histórico assume papel fundamental na sociedade capitalista, o indivíduo/trabalhador passa a se identificar unicamente como mercadoria, suas qualidades individuais e humanas são reduzidas em seu sentido para a produção. E nesse movimento, as possibilidades oriundas da tomada de consciência de classe passam a ser dissolvidas pelo discurso da particularização/individualização dos processos sociais.

[...] para que os dominados se emancipem, precisam formar e organizar a sua classe, reconhecer a existência de seu oposto que é a classe dominante, e, a partir disso procurar, através da luta, ocupar seu lugar, ultrapassar a natureza da dominação burguesa, minoritária e, instituir a democracia da maioria, pondo em movimento a lei dialética da quantidade e qualidade (BOGO, 2010, p. 10).

É na tarefa de manter a estrutura capitalista intocada que seus antagonismos fundamentais passam a ser inteiramente deslocados para o campo da individualização das relações. Para isso há a necessidade de planejamento, que de acordo com Mészáros (2011) ocupa lugar de destaque no sistema do capital, ao criar e articular estratégias de blindagem ao sistema social capitalista, o tornando duradouro e incontestável. É justamente nesse plano que se nega a condição de classe (real substrato do irreconciliável e definitivamente explosivo antagonismo do sistema do capital) e desloca-se o antagonismo social fundamental da sociedade capitalista para o plano da individualidade inerente às relações sociais, ou melhor, à sociedade civil.

[...] da perspectiva privilegiada do capital, era necessário desvirtuar, por um lado, a natureza real do insuperável antagonismo de classe - profundamente inerente ao arcabouço estrutural historicamente dado da sociedade e, da mesma forma, requerendo a sua transformação radical - como se fossem conflitos puramente individuais na "sociedade civil" (elaborada para tal propósito), cuja reconciliação não exigiria 
mudança estrutural alguma na sociedade efetivamente existente (MÉSZÁROS, 2011, p. 116).

Desse modo, apreende-se que a sobrevalorização da individualização das relações sociais em sua plena oposição à validade da concepção de classes tem resvalado no plano do real como uma forma de suplantar e direcionar alternativas, que não sendo estruturalmente contrária à manutenção da economia política do capital, reconciliaria relações irreconciliáveis do mundo da mercadoria. "Apenas uma agência supraindividual - seja ela a "mão invisível" de Adam Smith, o "espírito comercial" de Kant ou a "astúcia da razão" de Hegel - poderia cumprir tal reconciliação ideal do irreconciliável” (Idem, p. 117).

\section{Considerações finais}

É a partir da grande importância dada a novas formas de se compreender a expansão da liberdade humana e de suas manifestações pluralistas e, por isso, individuais, que há hoje uma sobrevalorização do que se entende por proposições inclusivas e democráticas. Ao serem articuladas ao domínio de um discurso sobremodo conservador, essas proposições formam as bases teóricas para a sustentação de políticas que veiculam ideais burgueses travestidos de um sentido altamente humanitário e social. Por definição histórica, o que estabelece a diferença entre classes, e sua possível definição identitária, são as forças totalizadoras das relações capitalistas de produção, e não diferenças de caráter sexual, étnico ou cultural como apregoam as proposições pluralistas dos pós-modernos ${ }^{3}$. A consciência da diferença entre classes é absolutamente insubstituível no processo de superação das bases antagônicas do capital, "[...] Uma classe é a condição para a existência da outra na luta da própria superação" (BOGO, 2010, p. 10).

\footnotetext{
${ }^{3}$ Mediante o entendimento de classes, a emancipação humana só pode ser compreendida a partir do próprio fim da sociedade capitalista, ou seja, sua objetivação é indiscutivelmente incompatível com a natureza do capitalismo. Apesar de o capitalismo submeter todas as formas sociais a suas necessidades de acumulação, as "diferenças" pós-modernas não são absolutamente contrárias ao capitalismo, sua integração ao que se entende por "igualdade de oportunidades", a partir da concretização de uma igualdade do tipo formal, certamente representaria um êxito diante da dita "igualdade" tão almejada por esses movimentos (WOOD, 2011).
} 
As concepções pluralistas de liberdade se tornam altamente compatíveis com a produção de uma sociedade segundo uma totalidade social abrangente, que subsiste da exploração do trabalho a partir da geração e extração de mais-valia. É nesse sentido que a quebra do entendimento de sociedade civil a partir da noção de totalidade, reitera uma realidade discursiva que desagrega a estrutura capitalista a realidades separadas e estanques.

[...] o capitalismo, ao desenvolver o individualismo burguês, que lhe é inerente, deu origem a uma sociedade na qual as necessidades coletivas estão subordinadas as necessidades de enriquecimento privado, e na qual as necessidades humanas (coletivas e individuais) estão subordinadas ao complexo processo de acumulação do capital pelos burgueses. Desse modo, o capitalismo deu origem a indivíduos que perderam a noção da real dimensão genérica, social, das suas existências, ficando presas as mesquinhas patifarias, ao estreito e pobre horizonte da cumulação do capital. [...] a dimensão coletiva, genérica, foi massacrada pelo egoísmo e mesquinharia que caracterizam o burguês (LESSA; IVO, 2008, p. 48).

E, desse modo, a perda do sentido de totalidade tem sido extremamente instrumental à densificação dos interesses da acumulação, seja na perda da noção de classe, seja em sua rendição ao "fetichismo da mercadoria" e ao triunfo da sociedade do consumo (WOOD, 2011). E nesse contexto, perder de vista a totalidade sistêmica do capitalismo sob a anunciação de um sistema indeterminado de democracia, é contribuir para a fragmentação do conceito de classe, tanto em si quanto para $\mathrm{si}^{4}$.

\footnotetext{
${ }^{4}$ De acordo com Marx a "classe em si" se dá à medida que o capital transforma a massa em trabalhadores, e cria um ideal que passa a ser também o ideal comum às massas. Já a "classe para si" se dá no momento em que essa classe passa a defender os seus interesses, e não os do capital. "Uma classe é "em si" pelo simples fato de existir. Uma classe é "para si" quando toma consciência do que a distingue de outras classes, ou seja, quando adquire consciência de classe" (PENÃ, 2008, p. 120).
} 


\section{Referências}

BOGO, Ademar. Identidade e luta de classes. 2. ed. São Paulo: Expressão Popular, 2010.

CARCANHOLO, Marcelo Dias. Dialética do desenvolvimento periférico: dependência, superexploração da força de trabalho e política econômica. Revista de Economia Contemporânea, v. 12, n. 2, p. 247-272, 2008.

CHESNAIS, F. A mundialização do capital. São Paulo: Xamã, 1996.

FOUCAULT, Michel. Microfísica do poder. Rio de Janeiro: Graal: 1979.

FONTES, Virgínia. Sociedade Civil no Brasil Contemporâneo: Lutas sociais e luta teórica na década de 1980. In: LIMA, J. C. F. e NEVES, L. M. W. (orgs.). Fundamentos da Educação Escolar do Brasil Contemporâneo. Rio de Janeiro: Fiocruz/EPSJV, 2006.

HARVEY, David; SOBRAL, A. U. Condição pós-moderna. Edições Loyola, 1998.

IASI, Mauro Luís. Ensaios sobre consciência e emancipação. 2. ed. São Paulo: Expressão Popular, 2011.

KONDER, Leandro. Marxismo e Alienação: contribuição para um estudo do conceito marxista de alienação. 2. ed. São Paulo: Expressão Popular, 2009.

LESSA, Sérgio; TONET, Ivo. Introdução à filosofia de Marx. São Paulo: Expressão Popular, 2008.

MÉSZÁROS, István. A crise estrutural do capital. 2. ed. Revisada e ampliada. São Paulo: Boitempo, 2011.

WOOD, E. Democracia contra o capitalismo: a renovação no materialismo histórico. São Paulo: Boitempo, 2011.

- Em defesa da história: O marxismo e a agenda pós-moderna.

Monthly Review, v. 47, p. 3, 1995. 